\title{
David Vygódski: modernismo e política no Brasil e na União Soviética
}

\author{
Bruno Barretto Gomide ${ }^{1}$
}

Uma rápida menção a um nome russo na correspondência de Mário de Andrade revela um dos momentos mais fascinantes das relações culturais entre o Brasil e a União Soviética, e também pode ajudar a iluminar alguns dos meandros das conexões, ainda pouco estudadas, entre o modernismo brasileiro e seus correlatos russos. David Vygódski figura em uma carta de Tarsila do Amaral a Mário, de 9 de julho de 1931. É um pedido de Tarsila, feito enquanto ainda estava em Leningrado, para que ele enviasse livros a Vygódski, que estava incumbido de preparar coletâneas e estudos sobre a literatura brasileira, inclusive para a Grande enciclopédia soviética (dado que parece ter impressionado a missivista e seu marido, que também sublinha o fato em uma passagem de Onde o proletariado dirige). Vygódski fora cicerone da pintora e de Osório Cesar durante a famosa viagem que empreenderam à União Soviética. Ao retornar ao Brasil, o casal fez solicitações similares a outros intelectuais, como Jorge Amado e Brasil Gerson. Todos prometem enviar livros, embora Mário, em sua resposta de 28 de agosto, não pareça muito entusiasmado com a idéia:

[...] mandei os meus livros pro tal de escritor russo, os do Alcântara, mandei recado pro Manuel Bandeira, que também se incumbiu de mandar de outros do Rio. O Gui também manda. ${ }^{2}$

Mário e os outros modernistas citados na carta aparentemente não encetaram correspondência com Vygódski. Se o fizeram, não foi

1 Professor de Literatura Russa no Departamento de Letras Orientais da Faculdade de Filosofia, Letras e Ciências Humanas da Universidade de São Paulo (USP, São Paulo, SP, Brasil). E-mail: bgomide@usp.br

2 Amaral, Aracy. Correspondência. Mario de Andrade \& Tarsila do Amaral. São Paulo: Edusp/IEB, 2001, p. 116. 
preservada no extraordinário arquivo do intelectual russo, que contém cerca de uma centena de cartas com diversos escritores ibero-americanos, inclusive com Tarsila, Osório, Amado e Brasil Gerson ${ }^{3}$.

Pela brevidade da aparição de Vygódski (e pelo tom meio condescendente de Mário), o leitor pode ser levado a imaginar que o personagem em questão é um mero funcionário da burocracia cultural soviética. Nada, porém, estaria mais longe da verdade. David Isaákovitch Vygódski (1893-1943), embora ainda pouco estudado pela russística internacional, é um dos intelectuais mais luminosos da cultura russa. Foi poeta, crítico, tradutor (de vinte idiomas) e um dos primeiros estudiosos da cultura latino-americana na Rússia. Teve conexões epistolares com vanguardas de diversos países e, do lado russo, foi um participante consistente dos principais movimentos e grupos artísticos, entre as décadas de 1910 e 1930, dentre os quais o formalismo, os Irmãos Serapião e os Oberiuti ${ }^{4}$.

Os quatro documentos a seguir são uma pequena mostra desse encontro "transoceânico" (segundo a definição de Jorge Amado), situado no cruzamento de propostas políticas, sociais e culturais modernistas.

O primeiro é a carta de David Vygódski a Mário de Andrade, datada de 22 de outubro de 1931 (ou seja, cerca de três meses depois do pedido de Tarsila e dois depois da confirmação de envio por Mário), em agradecimento pelos livros remetidos. É um documento inédito, disponível no acervo de Mário no IEB. Bom leitor de português, Vygódski não sabia escrever no idioma. Sua correspondência com intelectuais brasileiros é feita em espanhol e, ocasionalmente, francês. Nota-se a felicidade do hispanista russo ao obter os preciosos materiais, cuja obtenção era tão difícil naquelas circunstâncias. Trocas culturais com o exterior eram monitoradas cuidadosamente na URSS. Na ponta latino-americana do intercâmbio, qualquer correspondência com a Rússia era, desde 1917, vista com extrema suspeita. A correspondência vygodskiana está cheia de lamentos de escritores venezuelanos, colombianos, uruguaios, equatorianos, argentinos e brasileiros quanto ao sumiço de livros e documentos, eliminados pelas vicissitudes da longa viagem e pela ação dos agentes de censura. Para conseguir materiais, Vygódski

3 A correspondência foi reunida pelo autor deste texto e constará em um livro intitulado: David Vygódski: a correspondência ibero-americana (no prelo). O arquivo de Vygódski está depositado na Biblioteca Nacional Russa, em São Petersburgo.

4. Sobre a vida e a obra de Vygódski, cf. GOMIDE, Bruno. David Vygódski: a voz solitária de uma biblioteca. Kinoruss, São Paulo, ano 2, n. 3, 2012; David Vygódski e um “conto cinematográfico”. Kinoruss, São Paulo, ano 3, n. 4, 2013; . David Vygódski e o "Tartarin de Lisboa”. RUS, São Paulo, n. 2, 201z. Disponível em: <http:// www.usp.br/rus/images/edicoes/Rus_noz/14_GOMIDE-B-Vygodski-rev.pdf >. Acesso em: 23 mai. 2014 . 
montou, a custo, uma extensa rede de correspondentes. Valeu-se também dos contatos com os visitantes à URSS e da sua atuação em instituições soviéticas como a VOKS (Sociedade para as relações culturais com o exterior). Na década de 1920, publicou anúncios em revistas e jornais de grande circulação, pedindo o envio de materiais (muitos dos livros que recebeu foram fruto de uma nota veiculada no Le monde). E, desde seus primeiros contatos com o exterior, utilizou os canais de comunicação esperantistas, corrente à que pertencia desde a juventude e da qual era entusiasta.

O segundo documento é a relação de poemas brasileiros traduzidos por Vygódski com vistas a uma antologia de poesia latino-americana. As traduções foram feitas entre 1927 e 1932. Uma delas, a "Moda dos quatro rapazes", é o terceiro documento.

O último texto é a tradução do esboço de artigo de Vygódski intitulado "Literatura brasileira". São quatro folhas datilografadas e sem data, mas certamente posteriores a 1934 (pelo tom ideológico mais acirrado, devem pertencer ao período de 1935 a 1937, antes da prisão do autor). Apesar da veia partidária e do caráter fragmentário, é um texto fascinante por indicar, nas entrelinhas das duas peças resenhadas (Deus lhe pague, de Joracy Camargo, e Carne para canhão, de Afonso Schmidt), que Vygódski estava a par da situação do teatro brasileiro. Mostra também que o autor russo conhecia, para criticá-la, a poesia inicial de Schmidt. E vale por apresentar, ainda que brevemente, a mão de tradutor de Vygódski, eficiente, por exemplo, na versão russa nem um pouco literal dos idiomáticos títulos das peças.

Como em toda e qualquer análise de trajetória intelectual do período soviético, a questão premente é equacionar, no tempo e no espaço, o aspecto artístico e o ideológico, a passagem do finíssimo poliglota Vygódski para o propagandeador da ultradidática peça de Schmidt (ressaltando, contudo, a maior qualidade da peça de Camargo). O segundo aspecto se impõe sobre o primeiro, chegando a apagá-lo, ou eles se fundem em uma nova identidade? Em que medida um já estava prefigurado no outro? E, fundamentalmente, qual o grau de coerção estatal e social nesse processo? Sem dúvida, ela não explica integralmente o fenômeno, como propunham as leituras "totalitárias" da experiência soviética. São problemas evidentemente complexos, nos quais a presente documentação pode apenas resvalar. No primeiro documento, por meio da suave e despolitizada carta de agradecimento a Mário de Andrade, escrita à maneira de um professor erudito. Em seguida, com a lista de poemas traduzidos, uma interessante mescla de textos de orientações políticas e estéticas distintas - no geral, uma lista razoavelmente 
representativa e nem um pouco dogmática, contendo Mário de Andrade, Murilo Mendes, Jorge de Lima, Afrânio Peixoto, Álvaro Moreira, Manuel Bandeira, Ronald de Carvalho, Machado de Assis e Tasso da Silveira. Por fim, à medida que a repressão política na União Soviética recrudesce e desponta o tom altissonante trazido pela Guerra Civil Espanhola, evento central para o percurso final de Vygódski, temos o fragmento teatral, cujo parágrafo final sobre o destino de Schmidt - o intelectual etéreo que depois entra nos eixos - reverbera o do próprio Vygódski.

\section{Carta de David Vygódski a Mário de Andrade}

Leningrad 22/X/31

Señor Don Mario Andrade [sic]

S. Paulo

Muy Señor mio y amigo:

Recebi sus libros de poesia y de prosa y le agradisco muchisimo. Para un latinoamericanista ruso lo que le impede mucho está la falta de los libros y periodicos que no llegam em Rusia que por ocasion raro. Los señores Tarsila e César Ossorio [sic] ficando en Leningrad me han prometido ayudarmme en mis labores enviandome libros de Brasil, incitando a los autores de este país.

Lei con mucho gusto y con gran provecho los libros, especialmente de poesias pues estoy preparando una antologia de los poetas latinoamericanos y me agrada mucho de hacer conocer algunas de sus poesias a los lectores rusos. Espero hacerlo mas que una vez em mis ensayos y conferencias y sinto mucho que me faltaba la obra hacia esos dias.

Le agradesco una vez mas su amabilidade y su ayuda desinteresada y le ruego mucho de incitar los otros escritores de Brasil me manden sus libros. Eso facilitaria mis labores en favor de divulgación de las letras brasileñas en Rusia, donde no se sabe casi nada sobre las letras de Brasil.

Quedo su amigo que a. s. m.

David Vigodsky

[carimbo]

DAVID VIGODSKY

MOKHOVAIA N. 9, I

LENINGRAD 28 
"Manhã" - Guillerme de Almeida (13-7-1931).

"Ode ao burguês" - Mário de Andrade (2-11-1932).

"Moda dos quatro rapazes" - Mário de Andrade (30-5-1932).

"O rebanho" - Mário de Andrade (2-11-1932).

[Sem título] - Machado de Assis (4-8-1929).

"Irene no céu" - Manuel Bandeira (13-9-1932).

[Sem título] - Manuel Bandeira (13-9-1932).

"O Europeu" - Ronald de Carvalho (8-10-1932).

"Interior" - Ronald de Carvalho (14-?-1931).

"Poética" - Ronald de Carvalho (28-?-1927).

"Cinema de arrabalde" - Ribeiro Couto (14-9-1932).

[Sem título] - Ribeiro Couto (25-?-1931).

[Sem título] - Ribeiro Couto (14-9-1932).

"Lenin no futuro" - Correia Lima (21-3-1931).

"Diálogo sobre a felicidade" - Ribeiro Couto (15-9-1932).

"Os ciganos" - Jorge de Lima (28-2-1931).

"[Súplica?]" - Alvaro Moreira (5-2-1930).

[Sem título] - Murilo Mendes (8-?-1931).

"História do Brasil" - Afrânio Peixoto (março ou maio de 1932).

[Sem título] - Afrânio Peixoto (sem data).

[Sem título] - Afrânio Peixoto (sem data).

[Sem título] - Afranio Peixoto (março ou maio de 1932).

[Sem título] - Afranio Peixoto (março ou maio de 1932).

[Sem título] - Afranio Peixoto (março ou maio de 1932).

[Sem título] - Afranio Peixoto (março ou maio de 1932).

"Compaixão" - Tasso da Silveira (25-10-1931).

"A professora" - Julio [?] (1-11-1932).

[Sem título] - Julio [?] (1-11-1932).

5 Arquivo de David Isaákovitch Vygódski. Biblioteca Nacional Russa. Setor de Manuscritos. Fundo 1169, diélo 233. A pasta apresenta, além da relação acima transcrita, as traduções dos poemas para o russo. As lacunas nas informações se devem à caligrafia, por vezes indecifrável, de Vygódski. As datas são do próprio Vygódski. Os poemas estão listados na ordem em que aparecem na pasta. Em alguns casos, traduzi o título diretamente do russo, sem localizar o título original em português. Além dos versos brasileiros, há, por engano, um poema ("A Rosevelt") de Ruben Darío. 
A "Moda dos quatro rapazes" (na tradução russa de D. Vygódski)

\section{Песня четырех парней}

Мы четыре парня

В этом домике пустом

Мы четыре друга

В этомдом ике пустом

Мы четыре брата

В этомд омике живем

Зашуршала б юбка

Вот бы полон стал наш дом!

Только где четыре друга! 


\section{Artigo sobre literatura brasileira (sem data) ${ }^{6}$}

[...] e quando eu me recuperar, tentarei convencer o pai a respeito das minhas novas idéias".

O autor coloca a questão com mais clareza e obriga Cristo a convencer seus interlocutores de que é necessário fazer a revolução que colocará um fim à propriedade privada e socializará os meios de produção.

Todas as ideias e palavras de ordem revolucionárias soam, contudo, pouco convincentes precisamente em função de quem as pronuncia. Embora dotado de "retidão leninista", Cristo é um ser alheio ao que ocorre no mundo. Todas as palavras resultam ocas e as ideias, inconvincentes (mas isso o autor não percebe), porque não afloram do grupo social que deveria compreendê-las, nem da classe que as contém. Elas emanam de uma personalidade subsocial, que embora seja coerente e argumente de modo saudável, não pode suportá-las.

Para a comprovação enfática de suas aspirações elevadas, Brasil Gerson se vale de uma abordagem pequeno-burguesa dos ideais e fatos, uma abordagem que, em tese, ele recusa. E suas peças ficam encalacradas a meio caminho entre o burguês crente, que terá uma relação blasfema com a religião e uma evidente empatia com Marx, e o proletariado, para o qual semelhante contraposição Cristo-Marx é incabível e para o qual a resolução das questões colocadas pelos autores se encaminha de modos diversos e por outras vias.

Não sabemos qual a acolhida que foi reservada às peças de Gerson, sequer sabemos se elas já apareceram na imprensa ou nos palcos. Mas sem dúvida a peça Deus lhe pague, de outro autor, Joracy Camargo, granjeou uma recepção calorosa e suscitou uma grande quantidade de artigos e resenhas.

Do ponto de vista literário, é compreensível. A peça de Camargo, por sua construção dramática, é superior à obra de Gerson. Se este último cria um diálogo vivo e consideravelmente aguçado, situações inteligentes, surpresas que volta e meia causam espécie, então tudo isso se encontra [...]

[...] pela vida. De dia, ele recolhe esmolas. Ademais, aprendeu tão bem o assunto que acaba por reunir uma enorme quantia:

6 Arquivo de David Isaákovitch Vygódski. Biblioteca Nacional Russa. Setor de Manuscritos. Fundo 1169, diélo 63. Tradução de Bruno Gomide. 
trata-se de um ricaço. De noite, ele retorna para seu apartamento fartamente mobiliado e expõe para a esposa suas opiniões sobre a vida, sem revelar-lhe a sua profissão. Esse sábio e tranquilo mendigo se vinga, através de sua pobreza, do mundo dos exploradores e dos parasitas por aquelas humilhações que ele lhe trouxe (o dono da fábrica na qual ele quando jovem trabalhou afanou-lhe a invenção que devia dar-lhe riqueza e glória). Ele não quer trabalhar nesse mundo, não quer participar de sua construção, prefere apenas sugar, recolher-lhe o tributo, como se fosse alguém superior e independente em relação às leis e fora do seu sistema.

Não é difícil ver que esse protesto contra o mundo burguês é um protesto solipsista que não leva a lugar nenhum e se dissolve no pó da fuga individualista do mundo. Assim, sem negarmos o mérito de Camargo na criação de um teatro social brasileiro, no amplo sentido da palavra (mérito de modo algum pequeno, se tivermos em mente a mediocridade do teatro brasileiro, na sua deplorável condição presente), somos obrigados a recusar qualquer significado revolucionário - no nosso entendimento da palavra - para as suas peças. Para o nosso tempo, em anos de luta de classe acirrada em todo o mundo, as palavras de ordem revolucionárias não se podem construir apenas pela negativa. Ser contra em nossos dias já não é suficiente, é preciso ser a favor ${ }^{7}$.

Esse a favor, que não existe em Camargo, também não existe no poeta a que já nos referimos, em seu drama "Carne para canhão". "Essa peça, relata o autor, não foi encenada, e dificilmente o será tão cedo. Talvez nunca seja, porque no dia em que se puder dizer livremente tais coisas em voz alta, elas, por isso mesmo, perderão o seu significado". E fica evidente o motivo de a peça de Camargo ter ressoado centenas de vezes nos palcos, causando furores no espectador pequeno-burguês, numa época em que Schmidt não conseguia montar a sua peça e que dificilmente o consiga na situação atual.

Para começo de conversa, não o permitirão os representantes do capital estrangeiro, possuidores de uma influência decisiva na política brasileira. Não admitirão tamanho insulto, não tolerarão a exposição pública de suas tarefas predatórias, o alvo do autor. A burguesia local também não admitirá, a burguesia inquinada pelo autor de lacaia do capital estrangeiro, vivendo em completa incompreensão das tarefas nacionais do país, se entendermos por essa

$7 \quad$ Grifos de David Vygódski. 
palavra não um pequenino grupelho de manda-chuvas, mas, sim, uma população de 40 milhões. Também não o permitirá "uma das mais úteis e disponíveis forças da burguesia capitalista: o proletariado intelectual", acusado pelo autor de empregar suas mãos de obra na corrupção, na falta de princípios, na macaqueação do discurso sobre a "velha hostilidade do Paraguai" e o ódio histórico da Argentina. Um proletariado que, contra os próprios interesses, propagandeia a guerra imperialista, ora em relação aos seus vizinhos, ora ao horrendo espectro da União Soviética.

A peça de Schmidt, talvez demasiado esquemática, às vezes com personagens excessivamente simplificados na retidão de sua conduta, é decidida e ousada na questão da guerra imperialista e a resolve de modo exato no plano revolucionário da classe.

Quem são os principais instigadores e fomentadores da guerra? O capitalista estrangeiro, fornecedor de equipamentos de guerra; o rei local do petróleo; o arcebispo. São precisamente eles, pois o presidente, representante do governo, não possui papel nenhum, não passa de um brinquedo das forças de classe que podem substitui-lo, engendrar um golpe a qualquer minuto e trocá-lo por outro mais obediente. Nesse entendimento da essência de classe, da subordinação de classe do governo, reside um dos grandes méritos de Schmidt.

Na mesma situação submissa encontra-se Felício, intelectual cujo perfil traçamos acima. O autor o elabora mais do que os restantes, talvez vendo nele o seu passado, já reavaliado e descartado.

Quem é contra a guerra? O menino garçom que serve aos senhores, o proletário que se sente uno com a massa proletária, que conhece sua conexão de classe e o caráter comum entre os objetivos e os dos trabalhadores do porto, e a estenógrafa da fábrica, um autêntico e honesto "proletário intelectual" que compreende o seu devido lugar na disposição das lutas de classe e não o vende a preço de bananas em troca de um posto tranquilo e bem pago.

Ela vai se tornando mais decidida, mais ousada, mais resoluta. Quando já troveja o incêndio da guerra atiçado pelos fascistas, ei-la indo para a morte certa, e utilizando o seu último minuto para gritar à carne de canhão enviada para a batalha:

Eu conheço a verdade. Passei muitas noites com os livros de Marx, Engels e Lênin. E não apenas isso! Convivi com os caixeiros viajantes do imperialismo. Presenciei como se 
deslanchou a intriga do golpe militar fascista há um mês no hotel Washington. Vi como compraram o Felício e como ele se vendeu. Vocês, trabalhadores, camponeses, soldados e marujos, são mandados para a morte de maneira calculada, seu sangue se converterá em moedas de ouro. São eles, ela se apressa a dizer, ao mostrar o grupo de senhores da guerra que agora a mandam para a execução. Eis aí os agentes do capitalismo, os mesmos que organizam a guerra como se fosse uma partida de futebol, a guerra na qual todos morreremos e cujos gastos serão todos pagos pelo proletariado. ${ }^{8}$

Se cotejarmos tudo isso com os poemas anteriores de Schmidt (a sua primeira coletânea saiu há mais de vinte anos) com aqueles poemas onde o lugar predominante cabia aos beijos, rosas, frascos de perfumes, Evas e paraísos, então diante de nós claramente se delineia a figura, típica dos nossos dias, de um intelectual que muda de trilhos.

8 [N.E.] Na versão enviada pelo autor (Bruno Gomide), o destaque a esse trecho da transcrição é dado apenas por uma linha colocada antes e outra depois do mesmo. Optou-se por utilizar o recuo por uma questão de paronização da revista. 